\title{
Protective effect of Salvia miltiorrhiza Bunge on 5-fluorouracil-induced oral mucositis
}

\author{
DO RIM KIM ${ }^{1 *}$, JINSUNG KIM ${ }^{2 *}$, JA YOUNG OH $^{3}$, HA YOUNG KIM ${ }^{1}$, \\ YOUNG JOO KIM ${ }^{1}$ and MUN SEOG CHANG ${ }^{1}$
}

\begin{abstract}
Departments of ${ }^{1}$ Prescriptionology and ${ }^{2}$ Gastroenterology, College of Korean Medicine, Kyung Hee University; ${ }^{3}$ Department of Gastroenterology, Graduate School, Kyung Hee University, Seoul 130-701, Republic of Korea
\end{abstract}

Received March 23, 2016; Accepted April 28, 2017

DOI: $10.3892 /$ ijmm.2017.2999

\begin{abstract}
Oral mucositis is a common side-effect caused by chemotherapy or radiotherapy occurring in the majority of cancer patients and is characterized by inflammation and ulcers in the oral mucosa. In the present study, we examined the protective effects of Salvia miltiorrhiza Bunge (SM) on oral mucositis induced by 5 -fluorouracil (5-FU) in human pharyngeal cells and golden Syrian hamsters. We investigated the proliferation and antioxidant abilities of SM using MTT, 2-diphenyl-1-picrylhydrazyl (DPPH) and reactive oxygen species (ROS) assays in vitro. Additionally, TUNEL assay was performed, and the expression levels of nuclear factor $-\kappa \mathrm{B}(\mathrm{NF}-\kappa \mathrm{B})$, caspase-3 and proinflammatory cytokines were assessed by immunoblotting. The results showed that SM increased the cell proliferation rate in human pharyngeal cells up to $128.97 \pm 9.7 \%$ compared with this rate in the untreated cells and exerted protective effects on mucosal injury caused by 5-FU treatment. In addition, all concentrations of SM increased DPPH scavenging ability and blocked ROS generation in the treated cells. Taken together, following SM treatment, expression of NF- $\kappa \mathrm{B}$ and cleaved caspase-3 were significantly decreased followed by inhibition of cell death. These data suggest that SM could be used for the prevention and treatment of oral mucositis caused by cancer therapies.
\end{abstract}

\section{Introduction}

Oral mucositis is inflammation of the oral and oropharyngeal mucosa and usually occurs as a side-effect of cancer chemo-

Correspondence to: Professor Mun Seog Chang, Department of Prescriptionology, College of Korean Medicine, Kyung Hee University, 26 Kyunghee-daero, Dongdaemun-gu, Seoul 130-701, Republic of Korea

E-mail: mschang@khu.ac.kr

${ }^{*}$ Contributed equally

Key words: oral mucositis, Salvia miltiorrhiza Bunge, chemotherapy, 5-fluorouracil, reactive oxygen species, nuclear factor- $\kappa \mathrm{B}$, caspase-3 therapy or radiotherapy in the head and neck region (1). This condition affects $10-40 \%$ of patients receiving the standard dose of chemotherapy for tumors and $60-100 \%$ of patients undergoing myeloablative chemotherapy for hematopoietic stem cell transplant and high-dose radiation therapy $(2,3)$. Symptoms include pain, vomiting, dry mouth and diarrhea, and sequentially secondary infection of the oral mucosa leading to decreased quality of life $(3,4)$. Oral mucositis can reduce the effectiveness of chemotherapy as a result of the alteration or discontinuation of the chemotherapy (5). Therefore, the development of therapeutic agents that can be combined with chemotherapy to prevent oral mucositis as a side-effect of chemotherapy is crucial.

The incidence of oral mucositis is divided into five biological steps: initiation, upregulation and generation of messenger signals, signal amplification, ulceration and healing (6). Chemotherapy-induced damage to cells or tissues is caused by reactive oxygen species (ROS) (7), thus ROS play a main role in the initiation phase of oral mucositis and activate several transcription factors such as nuclear factor- $\kappa \mathrm{B}(\mathrm{NF}-\kappa \mathrm{B})$, a key transcription factor involved in the development of mucositis. $\mathrm{NF}-\kappa \mathrm{B}$ increases the production of proinflammatory cytokines, such as tumor necrosis factor (TNF)- $\alpha$, interleukin (IL)-1 $\beta$, IL-6, and induces apoptosis $(8,9)$. Upregulation of proinflammatory cytokines amplifies the primary damage (10). Recently, mechanistically based oral mucositis drugs were evaluated and developed such as keratinocyte growth factor (KGF), benzydamine $\mathrm{HCl}$ and $\mathrm{COX}-2$ inhibitors (10-12).

The dried root of Salvia miltiorrhiza Bunge (SM) (Lamiaceae), has been used in Korea, China and Japan for the treatment of various diseases, including coronary heart disease (13), cerebrovascular disease (14), Alzheimer's disease (15), Parkinson's disease (16), renal deficiency (17), hepatocirrhosis (18), cancer (19) and bone loss (20). The antioxidant (21), antidiabetic (22) and hepatoprotective (23) effects of SM on apoptosis and inflammation were investigated in a rat model of stroke (24). However, knowledge regarding the effects of SM extract on oral mucositis is limited. The effects of SM on molecular mechanisms in vitro and in vivo need to be elucidated. In the present study, we examined whether SM could be used in the development of a novel therapeutic agent for the treatment of mucositis 
induced by 5 -fluorouracil (5-FU). To identify the effects of SM on human pharyngeal cells and hamster, we performed scavenging of free radical activities against 2,2-diphenyl1-picrylhydrazyl (DPPH), cell viability assay, ROS level measurements, TUNEL assay and immunoblotting.

\section{Materials and methods}

Preparation of SM extract. SM was purchased from Kyung Hee University Medical Center (Seoul, Korea). A 300 g sample of dried medicinal herb was boiled in 31 water for $2 \mathrm{~h}$ at $100^{\circ} \mathrm{C}$, and the suspension was filtered and evaporated under reduced pressure. The filtrate was lyophilized and yielded $69.1 \mathrm{~g}$ powder. The dried extract was dissolved in distilled deionized water (Millipore, Billerica, MA, USA) and vortexed for $2 \mathrm{~min}$ at room temperature.

\section{In vitro studies}

Human pharyngeal cell culture. Human pharyngeal cell line (Detroit 562, ATCC CCL-138) was purchased from the American Type Culture Collection (ATCC; Manassas, VA, USA). The Detroit 562 cell line was cultured in modified Eagle's medium (MEM) supplemented with $10 \%$ fetal bovine serum (FBS; both from Gibco-BRL, Grand Island, NY, USA), $100 \mathrm{U} / \mathrm{ml}$ penicillin and $100 \mu \mathrm{g} / \mathrm{ml}$ streptomycin at $37^{\circ} \mathrm{C}$ in a humidified atmosphere of $5 \% \mathrm{CO}_{2}$.

Cell viability and proliferation assays. Cell proliferation was determined using the MTT assay. The Detroit 562 cells were starved for $24 \mathrm{~h}$ and simultaneously treated with several concentrations of SM $(1,5,10,50$ or $100 \mu \mathrm{g} / \mathrm{ml})$ only or with several concentrations of SM plus $10 \mu \mathrm{M} 5$-FU. After $48 \mathrm{~h}$, the medium was removed, and the cells were incubated with 3-(4,5-dimethylthiazol-2-yl)-2,5-diphenyltetrazolium bromide (MTT) to measure metabolic activity. Spectrophotometric analysis at $450 \mathrm{~nm}$ to measure metabolic activity was performed using a microtiter plate reader (Molecular Devices, LLC, Sunnyvale, CA, USA).

ROS assay. ROS production was performed according to the protocol of the intracellular ROS assay kit (Cell Biolabs, Inc., San Diego, CA, USA). Cells were cultured in a 96-well cell culture plate and treated with several concentrations of SM $(1$, $5,10,50$ or $100 \mu \mathrm{g} / \mathrm{ml}$ ) with $10 \mu \mathrm{M} 5$-FU for $48 \mathrm{~h}$. Next, the cells pretreated with $1 \mathrm{mM} \mathrm{2',7'-dichlorofluorescein} \mathrm{diacetate}$ (DCFH-DA) were incubated for $60 \mathrm{~min}$ at $37^{\circ} \mathrm{C}$. After a brief incubation, the cell fluorescence was read on a fluorometric plate reader (Thermo Fisher Scientific, Inc., Waltham, MA, USA) at $480 / 530 \mathrm{~nm}$. ROS production was determined by comparison with the predetermined 2',7'-dichlorofluorescein (DCF) standard curve.

DPPH assay. Mixtures of $0.1 \mathrm{mM}$ 2,2-diphenyl-1-picrylhydrazyl (DPPH) solution with methanol and SM $(1,5,10,50$ or $100 \mu \mathrm{g} / \mathrm{ml}$ ) were incubated in the dark for $30 \mathrm{~min}$ at room temperature. After $30 \mathrm{~min}$, the absorbance at $517 \mathrm{~nm}$ was read for each sample on a microtiter plate reader (Molecular Devices, LLC). Radical scavenging activity was calculated using the following formula: DPPH radical scavenging activity $(\%)=[(\mathrm{AB}-\mathrm{AT}) / \mathrm{AB}] \times 100$; where $\mathrm{AB}$ is the absor- bance of the blank sample and AT is the absorbance of the tested extract solution.

\section{In vivo studies}

Animals and experimental protocol. Seven-week-old male golden Syrian hamsters (SLC, Inc., Hamamatsu, Japan) weighing 100-110 g each were used. The animals were housed in a specific pathogen-free environment with a $12 \mathrm{~h}$ light/dark cycle at the Center for Laboratory Animal Care and Use at Kyung Hee University. Animal care and experimental procedures conformed to the 'Guide for the Care and Use of Laboratory Animals'. The protocol for the induction of oral mucositis was modified on the basis of a previously published protocol (25). The protocols for the use of hamsters in this study were approved by the Institutional Animal Care and Use Committee (IACUC) of Kyung Hee University. Briefly, all the animals received intraperitoneal (i.p.) administration of $80 \mathrm{mg} / \mathrm{kg}$ of the chemotherapy drug 5-FU on day 0 , followed by i.p. administration of $60 \mathrm{mg} / \mathrm{kg} 5-\mathrm{FU}$ on day 2 . The cheek pouch of the animals was everted and the mucosa was irritated by superficial scratching with the tip of an 18 -gauge needle by the same operator on days 3 and 4 .

Experimental groups. The hamsters were randomly divided into six groups: normal group (vehicle-treated, $n=6$ ), control (5-FU $80 \mathrm{mg} / \mathrm{kg}$, i.p. $\mathrm{n}=6$ ), positive control ( $0.15 \%$ benzydimine $\mathrm{HCl}$, o.p. $\mathrm{n}=6$ ) and three groups treated with different concentrations of SM with $80 \mathrm{mg} / \mathrm{kg}$ of $5-\mathrm{FU}(5-\mathrm{FU}+\mathrm{SM}$ : 100,500 and $1,000 \mathrm{mg} / \mathrm{kg}$ of SM and 5-FU, o.p. $\mathrm{n}=6 / \mathrm{each}$ group). 5-FU was administered on days 1 and 2 from the beginning of the study and $\mathrm{SM}$ and benzydimine $\mathrm{HCl}$ were administered for 5 days a week for 2 weeks. The animals were weighed weekly in order to adjust the gavage volume and to monitor their general health.

Histological evaluation of oral mucositis. For histological studies, the cheek pouches were fixed overnight in Bouin's solution, dehydrated in 70, 80, 95 and 100\% ethanol, xylene and embedded in paraffin. Tissue sections $(5 \mu \mathrm{m})$ were prepared in order to perform hematoxylin and eosin (H\&E) staining. The sections were deparaffinized and rehydrated in xylene, 100, 95, 80 and 70\% ethanol. The sections were overstained with hematoxylin, usually 3-5 min and excess stain was rinsed off in deionized water. Then the sections were destained for a few seconds in acidic alcohol until the sections appeared red in color (usually 4-5 dips) and then rinsed briefly in deionized water to remove the acid. Hematoxylin-stained slides from the last tap water were rinsed and placed in $70 \%$ ethanol for $3 \mathrm{~min}$. Slides were placed in eosin for $2 \mathrm{~min}$ and then slides were put through 95 and $100 \%$ ethanol and xylene. After H\&E staining, the slides were mounted with Canada balsam.

TUNEL assay. 5-FU-induced cell death was investigated on the day 14 using the terminal deoxynucleotidyltransferase (TdT)-mediated dUTP nick end labelling (TUNEL) method (ApopTag ${ }^{\circledR}$, no. S7101; Merck Millipore, Darmstadt, Germany). Briefly, after deparaffinizing, the samples were rehydrated and incubated with $20 \mathrm{mg} / \mathrm{ml}$ proteinase $\mathrm{K}$ for $15 \mathrm{~min}$ at room temperature. Endogenous peroxidases were 

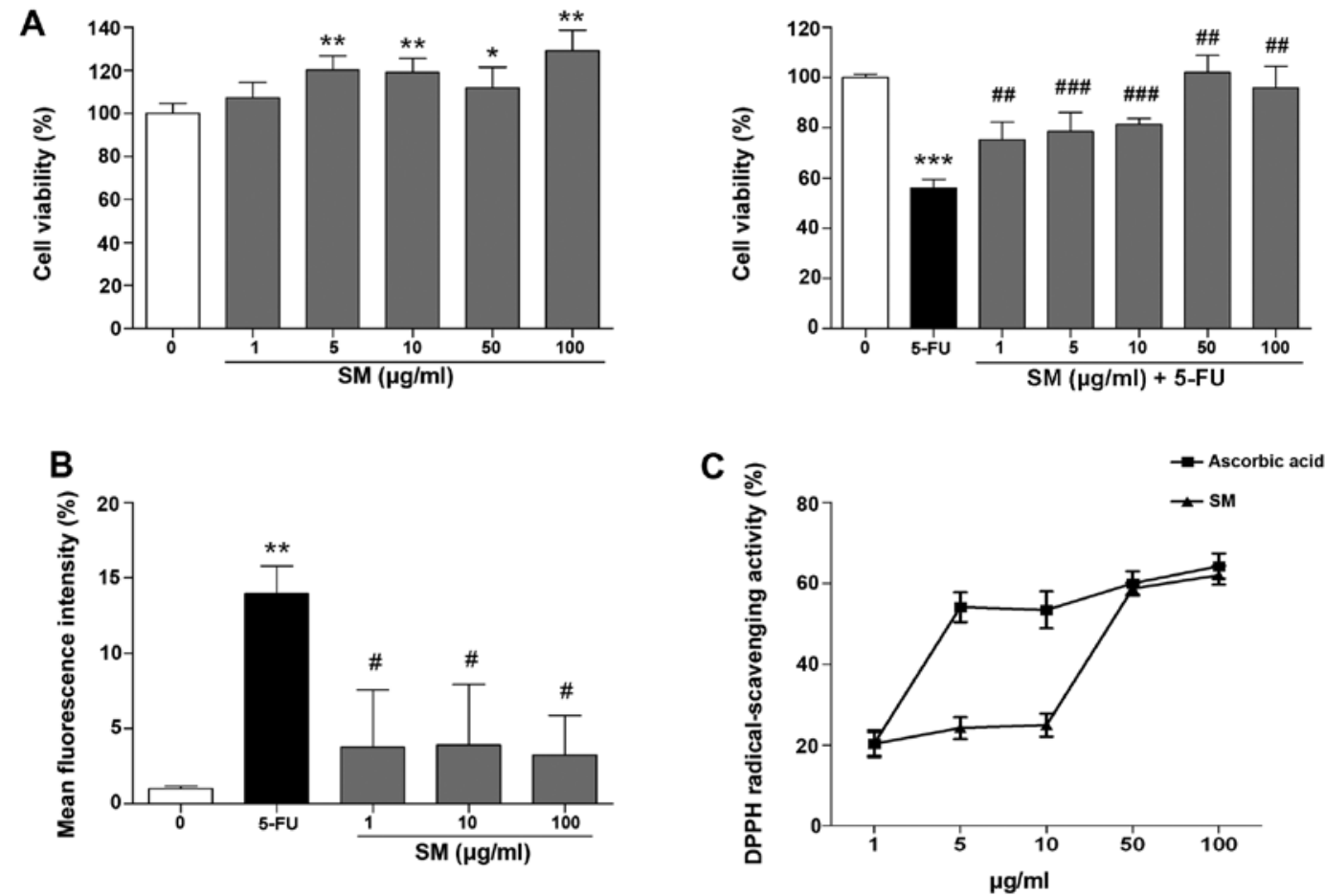

Figure 1. Effect of Salvia miltiorrhiza Bunge (SM) on 5-fluorouracil (5-FU)-treated human pharyngeal cells. (A) The effect of SM on the growth of a human pharyngeal cells. Human pharyngeal cells treated with SM were incubated in the presence or absence of $10 \mu \mathrm{M} 5$-FU at $37^{\circ} \mathrm{C}$ for $48 \mathrm{~h}$. (B) Effect of SM on 5-FU-induced reactive oxygen species (ROS) production. Normal represents untreated cells ( 0 ) and control represents $10 \mu \mathrm{M} 5$-FU (5'flu)-treated cells. (C) 2-Diphenyl-1-picrylhydrazyl (DPPH) scavenging ability of SM. Columns represent the means \pm SD $(n=3)$. Significantly different from the normal ( $\mathrm{p}<0.05$, $\left.{ }^{* *} \mathrm{p}<0.01,{ }^{* * *} \mathrm{p}<0.001\right)$. Significantly different from the control $\left({ }^{\#} \mathrm{p}<0.05,{ }^{\# \#} \mathrm{p}<0.01,{ }^{\# \# \#} \mathrm{p}<0.001\right)$.

blocked by treatment with $3 \%(\mathrm{v} / \mathrm{v})$ hydrogen peroxide in phosphate-buffered saline (PBS) for $5 \mathrm{~min}$ at room temperature. After washing, the sections were then incubated in a humidified chamber at $37^{\circ} \mathrm{C}$ for $1 \mathrm{~h}$ with TdT buffer containing TdT enzyme and reaction buffer. Specimens were incubated for $10 \mathrm{~min}$ at room temperature with a stop/wash buffer and then incubated in a humidified chamber for $30 \mathrm{~min}$ with anti-digoxigenin peroxidase conjugate at room temperature. After a series of PBS washes, the slides were covered with peroxidase substrate for color development and then washed in three changes of $\mathrm{dH}_{2} \mathrm{O}$ and counterstained in $0.5 \%$ (w/v) methyl green for $10 \mathrm{~min}$ at room temperature. The TUNEL-positive cells were counted (10 fields/slide; magnification, $\mathrm{x} 1,000)$ for statistical comparisons.

Western blotting. Proteins from homogenized cheek pouches of hamsters were separated using a nuclear extraction kit following a modification of the manufacturer's instructions (Active Motif, Carlsbad, CA, USA). SDS-PAGE and western blotting were performed as previously described (26). Samples for protein extraction were half of the same cheek pouches of hamsters used for RNA extractions. Equivalent amount $(50 \mu \mathrm{g})$ of protein extracts was separated on $10 \%$ Tris-glycine gels by SDS-PAGE and transferred to nitrocellulose membranes using $25 \mathrm{mM}$ Tris and $250 \mathrm{mM}$ glycine buffer containing $20 \%$ methanol, $\mathrm{pH}$ 8.3. Transfer was performed at a constant voltage of $120 \mathrm{~mA}$ for $1 \mathrm{~h}$. After transfer, the membranes were blocked in PBS containing $0.05 \%$ Tween-20 (PBS-T) with 5\% skim milk for $2 \mathrm{~h}$ at room temperature and incubated with the primary antibodies $(1: 1,000)$ for IL-1 $\beta$ (sc-12742), TNF- $\alpha$ (sc-1350),
NF- $\mathrm{B}$ (sc-109) and IL-4 (sc-32242) (all from Santa Cruz Biotechnology, Inc., Dallas, TX, USA) in PBS-T overnight at $4^{\circ} \mathrm{C}$. Following overnight incubation, the membranes were rinsed with $1 \mathrm{X}$ PBS three times and incubated with conjugated goat anti-rabbit IgG for $1 \mathrm{~h}$ at room temperature, followed by three additional washes with $1 \mathrm{X}$ PBS.

Statistical analysis. Statistical analysis was performed using GraphPrism 4.0.3 software (GraphPad Software, Inc., San Diego, CA, USA). Data are presented as means with standard deviation (SD) and analyzed using the statistical software SPSS, version 12.0 (SPSS, Inc., Chicago, IL, USA).

\section{Results}

SM enhances proliferation of the human pharyngeal cells. The effects of SM on proliferation of the Detroit 562 human pharyngeal cells were determined from cell growth kinetics using the MTT assay, which measures the metabolic activity of viable cells. Growth-arrested Detroit 562 cells were cultured in starvation medium for $24 \mathrm{~h}$ prior to the experiment and incubated for $48 \mathrm{~h}$ with SM and $10 \mu \mathrm{M}$ 5-FU. SM activated cell proliferation; specifically, the number of cells treated with $100 \mu \mathrm{g} / \mathrm{ml} \mathrm{SM}$ increased by $128.97 \pm 9.7 \%$ compared with that noted in the untreated cells $(\mathrm{p}<0.01$; Fig. 1A). The cell viability in the 5-FU and SM-treated groups (1, 5, 10, 50 or $100 \mu \mathrm{g} / \mathrm{ml}$ ) was significantly increased compared with the cell viability of the control $(10 \mu \mathrm{M} 5$-FU-only treated) group $(75.19 \pm 7.01,78.43 \pm 7.0,81.33 \pm 2.41,102.1 \pm 6.8$ and $95.97 \pm 8.54$ vs. $56.01 \pm 3.48 \%$, respectively; $\mathrm{p}<0.01$, Fig. $1 \mathrm{~A}$ ), indicating that 

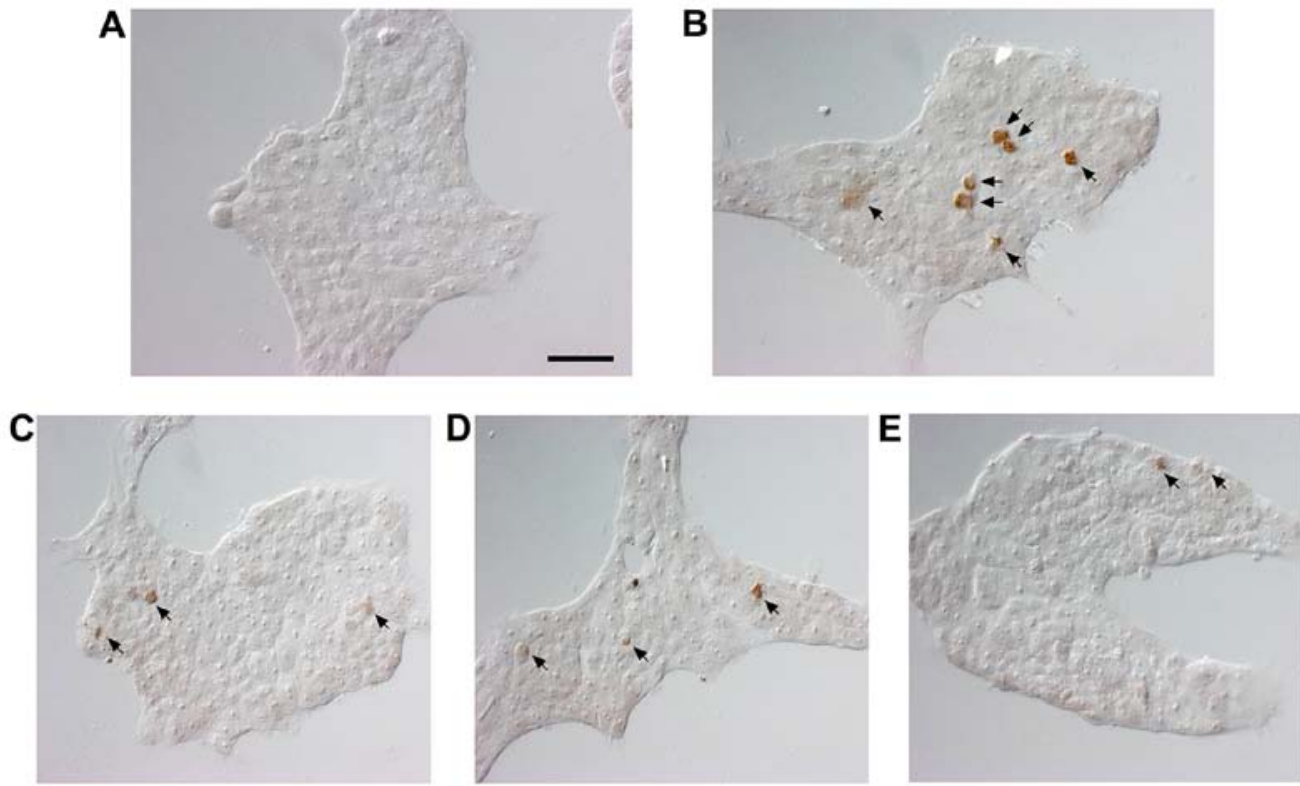

Figure 2. Effects of Salvia miltiorrhiza Bunge (SM) on 5-fluorouracil (5-FU)-induced apoptosis in human pharyngeal cells. TUNEL assays were performed to detect the apoptotic cells. Arrows indicate TUNEL-positive nuclei. Images were obtained at an objective magnification, x400. (A) Normal, (B) control (10 $\mu \mathrm{M} 5$-FU), (C) $1 \mu \mathrm{g} / \mathrm{ml} \mathrm{SM}+10 \mu \mathrm{M}$ 5-FU-treated group, (D) $10 \mu \mathrm{g} / \mathrm{ml} \mathrm{SM}+10 \mu \mathrm{M}$ 5-FU-treated group and (E) $100 \mu \mathrm{g} / \mathrm{ml} \mathrm{SM}+10 \mu \mathrm{M} 5$-FU-treated group.

SM enhanced the proliferation rate of Detroit 562 cells and exerted protective effects against 5-FU-induced cytotoxicity.

SM decreased intracellular ROS production and increases the $D P P H$-scavenging activity. As shown in Fig. $1 \mathrm{~B}$, the production of superoxide anions in the $10 \mu \mathrm{M} 5$-FU-treated cells was decreased markedly by co-treatment of 1,10 and $100 \mu \mathrm{g} /$ $\mathrm{ml}$ of SM compared with the (10 $\mu \mathrm{M} 5$-FU-only treated) control. Next, the effects of SM on DPPH-scavenging activity were assessed. The DPPH-scavenging activity increased to $20.30,24.21,24.95,58.65$ and $61.96 \%$ at $1,5,10,50$ and $100 \mu \mathrm{g} / \mathrm{ml}$ of SM treatment, respectively. The $\mathrm{IC}_{50}$ value of SM was $42.6 \mu \mathrm{g} / \mathrm{ml}$. As a positive control, we measured the effects of ascorbic acid (AC) on DPPH-scavenging activity, which increased to $20.35,54.08,53.39,59.95$ and $64.23 \%$ at 1 , $5,10,50$ and $100 \mu \mathrm{g} / \mathrm{ml} \mathrm{SM}$ concentrations, respectively. The $\mathrm{IC}_{50}$ value of AC was $4.6 \mu \mathrm{g} / \mathrm{ml}$ (Fig. 1C).

SM reduces apoptosis in the human pharyngeal cell line. Nuclear DNA breaks in human pharyngeal cells were detected using TUNEL staining to estimate the extent of apoptosis and assessed under magnification, $\mathrm{x} 400$. The results of the TUNEL staining showed positive staining for DNA fragmentation in the 5-FU-treated compared with the untreated cells (Fig. 2). The number of TUNEL-positive cells was reduced by 1,10 and $100 \mu \mathrm{g} / \mathrm{ml}$ following SM treatment.

$S M$ regulates apoptosis-related signaling pathways. We investigated whether SM is associated with NF- $\mathrm{BB}$ and caspase-dependent apoptosis. The NF- $\mathrm{KB}$ and caspase-3 signaling pathways were activated by 5 -FU treatment but were decreased by all concentrations of SM (Fig. 3).

Histological effects of SM on cheek pouches of hamsters. $\mathrm{H} \& \mathrm{E}$ staining was carried out to observe the histological changes in the cheek pouches. The normal group is the vehicle-treated group and the control is the $5-\mathrm{FU}(80 \mathrm{mg} / \mathrm{kg}$, i.p.) only treated group. Positive control is the benzydimine HCl-treated group. In addition, there were three co-treatment groups with SM $(100$, 500 and $1,000 \mathrm{mg} / \mathrm{kg})$ and $5-\mathrm{FU}(80 \mathrm{mg} / \mathrm{kg}$, i.p.). Histological examination demonstrated a normal arrangement of cellular components in the cheek pouches of the hamsters (Fig. 4A). Stratum corneum exfoliation, degradation of the epithelial layer and ulcers were observed in the control (Fig. 4B). The observed damages were recovered in the positive control (Fig. 4C) and the $500,1,000 \mathrm{mg} / \mathrm{kg}$ of SM-treated groups (Fig. 4E and F); epithelial layers were recovered.

Detection of apoptosis in cheek pouches of hamsters. To examine the apoptosis in cheek pouches of the hamsters, TUNEL staining was carried out. The cheek pouches of hamsters showed a significant increase in apoptotic changes in the group treated with 5-FU (Fig. 5B, arrow) when compared with the normal group (Fig. 5A), while the positive control group (Fig. 5C) and SM and 5-FU-treated groups showed epithelial layer and granular layer (Fig. 5D-F).

Effect of SM on the expression of IL-1 $\beta, T N F-\alpha, N F-\kappa B$ and caspase-3 in cheek pouches of hamsters. Western blotting was performed to determine the effect of SM on proinflammatory cytokines (IL- $1 \beta$ and TNF- $\alpha$ ), NF- $\kappa$ B and caspase- 3 expression level in cheek pouches of hamsters. As shown in Fig. 6, NF- $\kappa \mathrm{B}, \mathrm{TNF}-\alpha$ and IL-1 $\beta$ protein expression levels in the control group were increased compared to the normal group $(136.01 \%, \mathrm{p}<0.05 ; 141.5 \%, \mathrm{p}<0.05 ; 147.0 \%, \mathrm{p}<0.01$, respectively). NF- $\kappa B, T N F-\alpha$ and IL- $1 \beta$, protein levels in the positive control (benzydimine HCl-treated) group were decreased compared to the control group (94.7 vs. $136.0 \%, \mathrm{p}<0.01 ; 110.1$ vs. $141.5 \%, \mathrm{p}<0.01$ and 129.9 vs. $147.0 \%, \mathrm{p}<0.01$, respectively). In contrast, in the $1,000 \mathrm{mg} / \mathrm{kg} \mathrm{SM}$ and 5 -FU-treated 
A
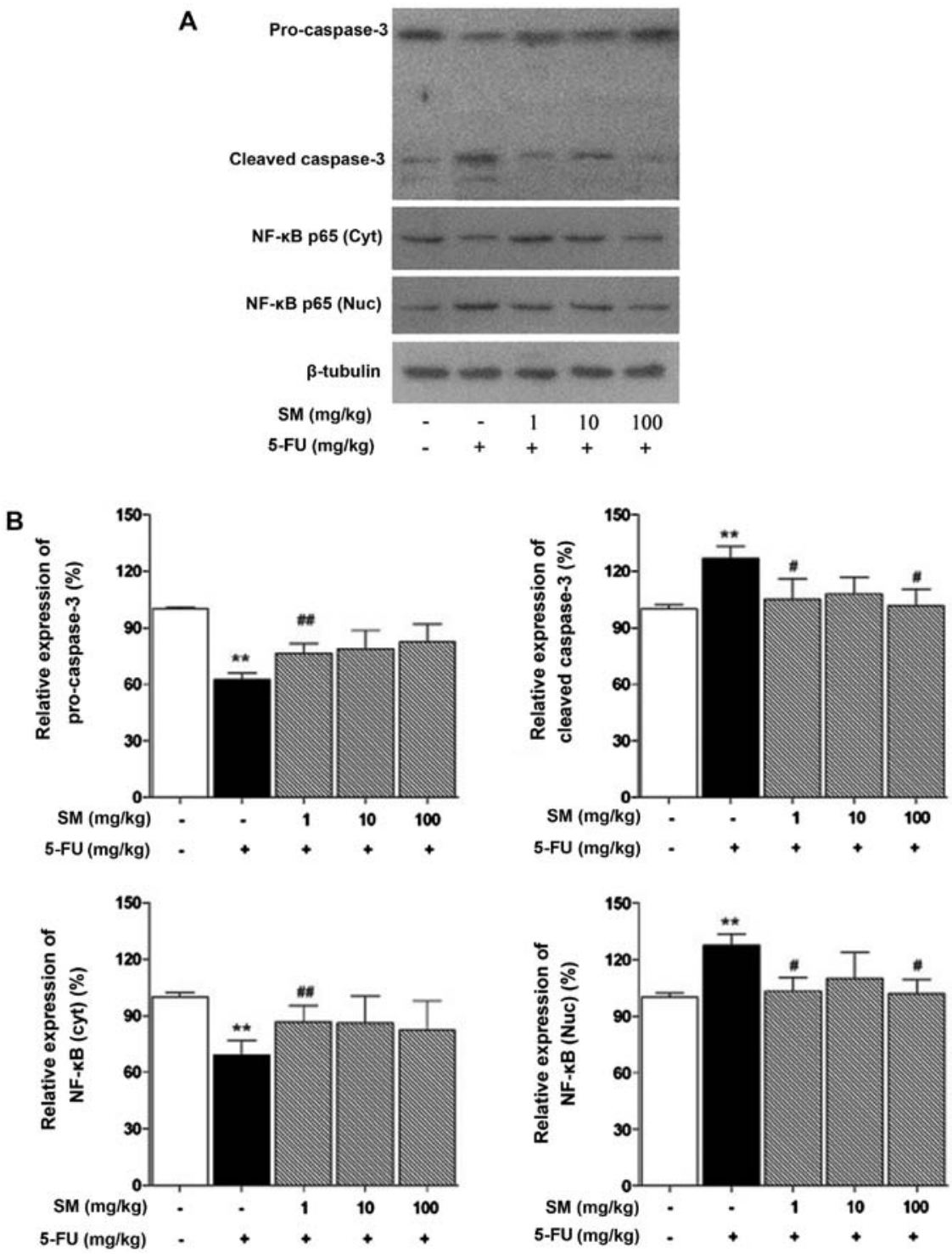

Figure 3. Immunoblot analysis of nuclear factor- $\mathrm{kB}(\mathrm{NF}-\mathrm{\kappa B})$ and caspase-3 proteins from 5-fluorouracil (5-FU)-induced apoptotic human pharyngeal cells after SM treatment. $\beta$-tubulin was used as the internal control. Western blot results of (A) NF- $\mathrm{\kappa B}$ and cleaved caspase-3 and (B) the relative expression levels.
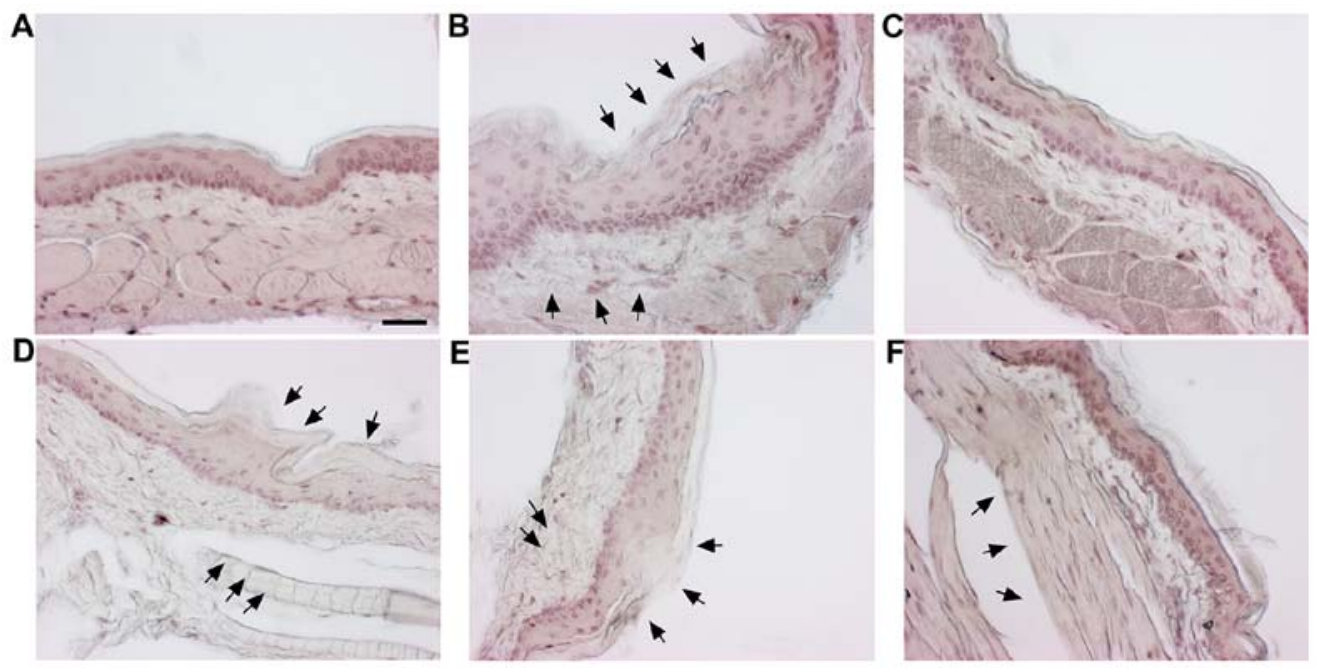

Figure. 4. Examination of histological changes in cheek pouches of hamsters using hematoxylin and eosin (H\&E) staining. (A) Normal (vehicle-treated) group, (B) control [5-FU ( $80 \mathrm{mg} / \mathrm{kg}$, i.p.) only], (C) positive control (benzydimine HCl-treated group), (D) $100 \mathrm{mg} / \mathrm{kg} \mathrm{SM}+5$-fluorouracil (5-FU)-treated group, (E) $500 \mathrm{mg} / \mathrm{kg} \mathrm{SM}+5$-FU-treated group and (F) $1,000 \mathrm{mg} / \mathrm{kg} \mathrm{SM}+5$-FU-treated group. Arrows indicate the histological changes in the epithelial layer, granular layer and muscle layer on the cheek pouches of the hamsters. Images were obtained at an objective magnification, $\mathrm{x} 200$. Scale bar, $200 \mu \mathrm{m}$. 

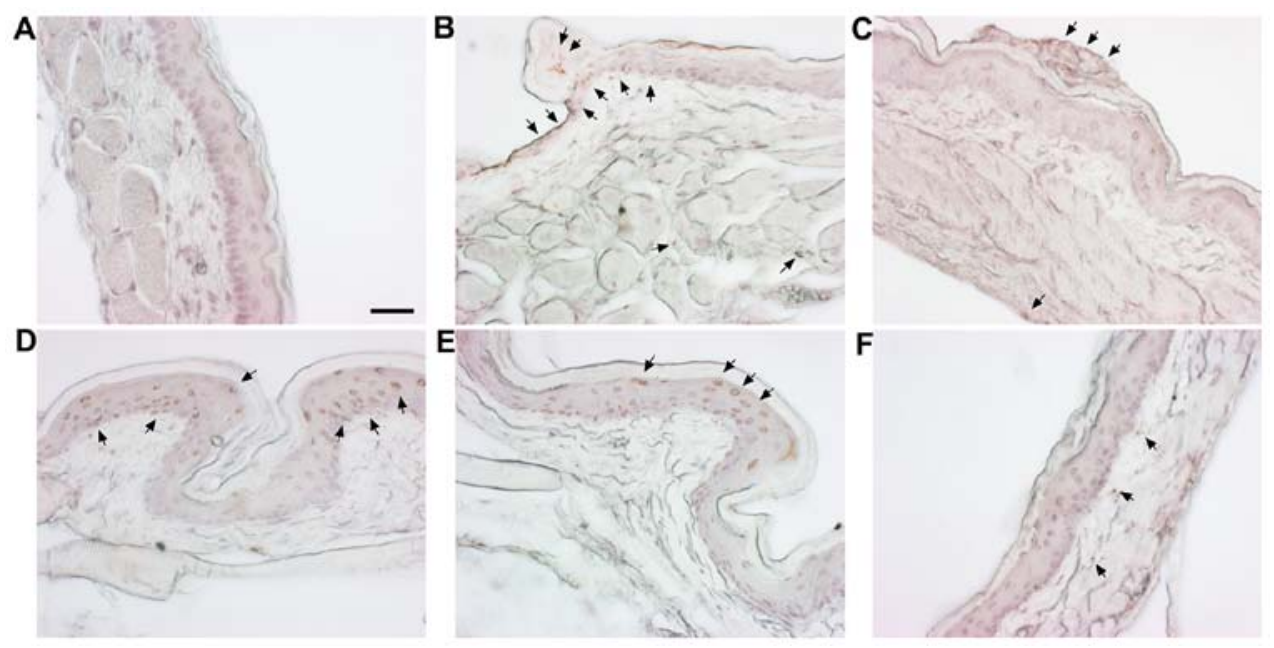

Figure 5. TUNEL assay in the cheek pouches of hamsters subjected to 5-fluorouracil (5-FU)-induced oral mucositis. (A) Normal (vehicle-treated) group, (B) control [5-FU (80 mg/kg, i.p.) only], (C) positive control (benzydimine HCl-treated group), (D) $100 \mathrm{mg} / \mathrm{kg} \mathrm{SM}+5$-FU-treated group, (E) 500 mg/kg $\mathrm{SM}+5$-FU-treated group and (F) $1,000 \mathrm{mg} / \mathrm{kg} \mathrm{SM}+5$-FU-treated group. Arrows indicate TUNEL-positive nuclei in the epithelial layer and granular layer on the cheek pouches of the hamsters. Images were obtained at an objective magnification, $\mathrm{x} 200$. Scale bar, $200 \mu \mathrm{m}$.

A

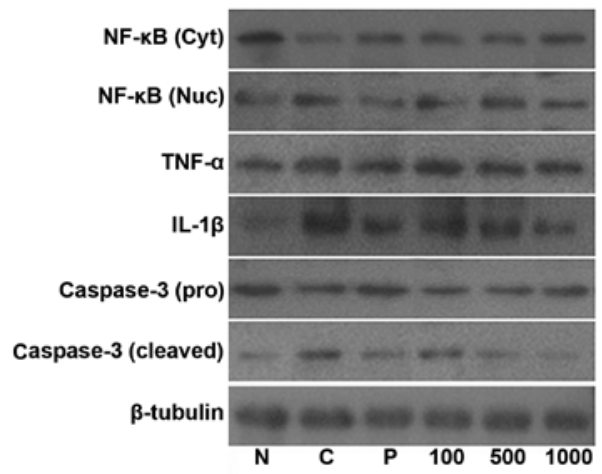

\section{B}
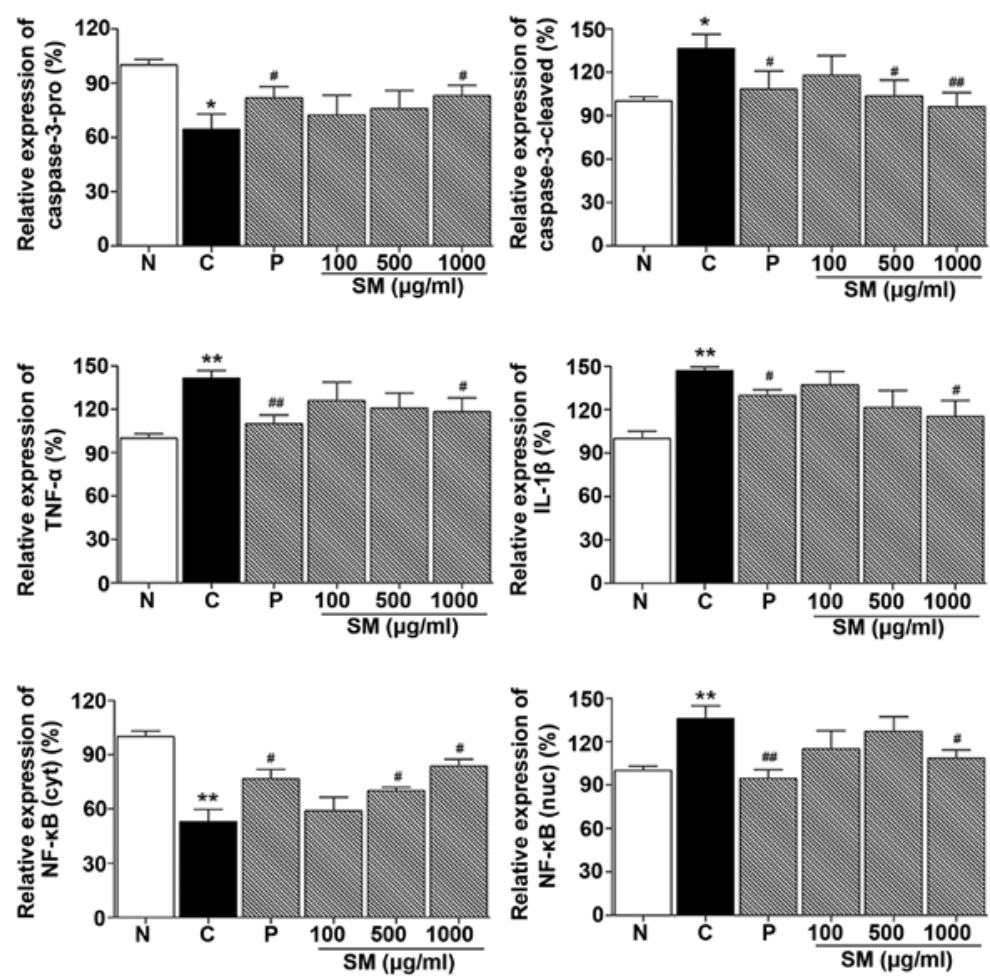

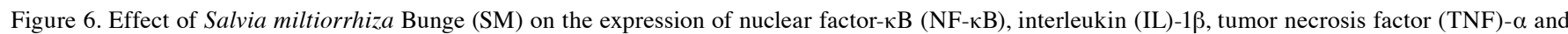
caspase-3 proteins in cheek pouches of hamsters. (A) Western blot showing the protein expression levels. (B) The western blot bands were quantified by normalization to those from the vehicle-treated group and individuals. Each column represents the mean \pm SD $(n=3)$. Significantly different from the normal

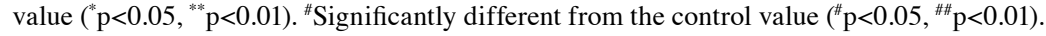


group, NF- $\kappa \mathrm{B}, \mathrm{TNF}-\alpha$ and IL- $1 \beta$ protein expression levels were significantly decreased when compared to these levels in the control group (108.7 vs. $136.0 \%$; 118.19 vs. $141.5 \%$; 115.3 vs. $147.0 \%$, p $<0.05$, respectively; Fig. 6).

Caspase-3 cleaved protein level in the control group was increased compared to that noted in the normal group (136.62, $\mathrm{p}<0.05$, respectively). This level was decreased in the positive control (benzydimine $\mathrm{HCl}$ ) group compared to the control group ( 108.3 vs. $136.6 \%, p<0.05$, respectively). In addition, in the SM and 5-FU-treated groups, caspase-3 protein expression was significantly decreased when compared with that noted in the control group $(103.7 \%, \mathrm{p}<0.05$ and $96.1 \%$, $\mathrm{p}<0.01$ vs. $136.6 \%$, respectively; Fig. 6).

\section{Discussion}

Cancer chemotherapy targets rapidly dividing cancer cells but also interferes with DNA, RNA and protein synthesis (27). Therefore, normal tissue cells as well as cancer cells are damaged. Oral mucositis is an adverse effect of cancer chemotherapeutic drugs (28). Ulceration of the oral mucosa and oropharynx can lead to decreased quality of life and modification with highly expensive cancer treatments (29). The use of current medications for mucositis such as palifermin and benzydamine is limited due to their high cost (30). Therefore, the development of new oral mucositis therapeutic drugs that can be universally used to promote effectiveness is necessary. Salvia miltiorrhiza Bunge (SM) is known for its antioxidative and anti-inflammatory effects $(22,23)$. However, the molecular mechanisms of SM are poorly understood, and its effects on oral mucositis have yet to be determined. In the present study, we investigated the effects of SM on 5-FU-induced oral mucositis.

5-FU is an anticancer drug which is used most frequently for carcinomas of the breast, colon, and skin (31). 5-FU inhibits thymidylate synthase or incorporation of nucleic acid into RNA and DNA and causes cell death. But it can induce oral mucositis. Therefore, inhibition or the prevention of the cytotoxic effects of 5-FU on the mucosa is a reasonable strategy (32).

In this study, we examined cell viability using an MTT assay, DPPH and ROS reproduction to determine the antioxidant activities of SM. Generation of ROS linked to increased oxidative stress causes oxidative damage and the pathogenesis of several diseases (33). ROS are an important mediator of downstream biological of oral mucositis (34). The antioxidant ability of natural products is crucial in oral mucositis treatment. SM promoted proliferation of human pharyngeal cells without cytotoxic effects. Additionally, SM showed protective effects against 5-FU-induced cytotoxicity and, as expected, stimulated cell growth.

The DPPH assay is widely used to assess free radical-scavenging abilities of natural products reflecting their antioxidant properties (35). SM reduced the stable radical DPPH to yellow-colored diphenylpicryl hydrazine dose-dependently. Based on this result, SM showed antioxidant activities against scavenging DPPH free radicals. Additionally, ROS production was effectively suppressed at all concentrations in the SM-treated cells. To further understand the antioxidant effects of SM on the human pharyngeal cell line, we examined ROS production. SM-treated cells showed significantly lowered ROS production implying that SM may protect mucosal injury initiated by ROS generation.

DNA strand breaks caused by ROS activate transcription

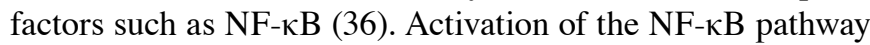
leads to the expression of antiapoptotic genes and induces proinflammatory cytokines (37). Additionally, these reactions cause oral mucositis. The biological steps of oral mucositis involve various pathways including those associated with mitogen-activated protein kinase (MAPK), ceramide and matrix metalloproteinases (MMPs) (38). Thus, therapeutic drugs for oral mucositis will help reduce apoptosis and recover epithelial cells in the oral mucositis. To examine the regulation of apoptosis by $\mathrm{SM}$ in our study, the $\mathrm{NF}-\kappa \mathrm{B}$ and caspase-independent apoptotic pathways were examined by immunoblotting using 5-FU-treated human pharyngeal cells and hamster cheek pouches. In the TUNEL assay, the number of apoptosis-positive cells in the SM-treated groups was decreased compared with the control, and SM treatment also reduced the expression of NF- $\mathrm{NB}$ and cleaved caspase- 3 both in vitro and in vivo. Several transcription factors and proinflammatory cytokines such as IL- $1 \beta$ and TNF- $\alpha$ are known to be involved in the development of mucositis (39). SM treatment for 14 days led to a decrease in the expression level of proinflammatory cytokines (IL-1 $\beta$ and TNF- $\alpha$ ) and NF- $\kappa$ B in the 5-FU-induced oral mucositis.

In conclusion, the present study demonstrated that SM promoted cell proliferation and had protective effects against oxidative stress. Additionally, SM inhibited apoptotic cell death mediated by the NF- $\mathrm{NB}$-caspase-3 signaling pathways. Moreover, changes in $\mathrm{NF}-\kappa \mathrm{B}$ and proinflammatory cytokine expression following SM treatment suggest that SM reduces inflammation during the development of mucositis. Although other molecular mechanisms remain to be elucidated in further studies, this study showed the possible use of SM as a therapeutic agent for oral mucositis.

\section{References}

1. Sonis ST and Fey EG: Oral complications of cancer therapy. Oncology (Williston Park) 16: 680-686, 2002.

2. Pico JL, Avila-Garavito A and Naccache P: Mucositis: its occurrence, consequences, and treatment in the Oncology setting. Oncologist 3: 446-451, 1998.

3. Bowen JM and Keefe DM: New pathways for alimentary mucositis. J Oncol 2008: 907892, 2008.

4. Loury D, Embree JR, Steinberg DA, Sonis ST and Fiddes JC: Effect of local application of the antimicrobial peptide IB-367 on the incidence and severity of oral mucositis in hamsters. Oral Surg Oral Med Oral Pathol Oral Radiol Endod 87: 544-551, 1999.

5. Sonis ST, Elting LS, Keefe D, Peterson DE, Schubert M, Hauer-Jensen M, Bekele BN, Raber-Durlacher J, Donnelly JP and Rubenstein EB; Mucositis Study Section of the Multinational Association for Supportive Care in Cancer; International Society for Oral Oncology: Perspectives on cancer therapy-induced mucosal injury: pathogenesis, measurement, epidemiology, and consequences for patients. Cancer 100 (Suppl 9): 1995-2025, 2004.

6. Raber-Durlacher JE, Elad S and Barasch A: Oral mucositis. Oral Oncol 46: 452-456, 2010.

7. Cheng KK, Goggins WB, Lee VW and Thompson DR: Risk factors for oral mucositis in children undergoing chemotherapy: a matched case-control study. Oral Oncol 44: 1019-1025, 2008.

8. Mantovani G, Macciò A, Madeddu C, Mura L, Massa E, Gramignano G, Lusso MR, Murgia V, Camboni P and Ferreli L: Reactive oxygen species, antioxidant mechanisms and serum cytokine levels in cancer patients: impact of an antioxidant treatment. J Cell Mol Med 6: 570-582, 2002. 
9. Sonis ST, Peterson RL, Edwards LJ, Lucey CA, Wang L, Mason L, Login G, Ymamkawa M, Moses G, Bouchard P, et al: Defining mechanisms of action of interleukin-11 on the progression of radiation-induced oral mucositis in hamsters. Oral Oncol 36: 373-381, 2000.

10. Sonis ST: The pathobiology of mucositis. Nat Rev Cancer 4: 277-284, 2004.

11. Beaven AW and Shea TC: Palifermin: a keratinocyte growth factor that reduces oral mucositis after stem cell transplant for haematological malignancies. Expert Opin Pharmacother 7: 2287-2299, 2006.

12. Kazemian A, Kamian S, Aghili M, Hashemi FA and Haddad P: Benzydamine for prophylaxis of radiation-induced oral mucositis in head and neck cancers: a double-blind placebo-controlled randomized clinical trial. Eur J Cancer Care (Engl) 18: 174-178, 2009.

13. Su CY, Ming QL, Rahman K, Han T and Qin LP: Salvia miltiorrhiza: traditional medicinal uses, chemistry, and pharmacology. Chin J Nat Med 13: 163-182, 2015.

14. Yu XY, Lin SG, Chen X, Zhou ZW, Liang J, Duan W, Chowbay B, Wen JY, Chan E, Cao J, et al: Transport of cryptotanshinone, a major active triterpenoid in Salvia miltiorrhiza Bunge widely used in the treatment of stroke and Alzheimer's disease, across the blood-brain barrier. Curr Drug Metab 8: 365-378, 2007

15. Zhang XZ, Qian SS, Zhang YJ and Wang RQ: Salvia miltiorrhiza: a source for anti-Alzheimer's disease drugs. Pharm Biol 54: 18-24, 2016.

16. Ren B, Zhang YX, Zhou HX, Sun FW, Zhang ZF, Wei Z, Zhang CY and Si DW: Tanshinone IIA prevents the loss of nigrostriatal dopaminergic neurons by inhibiting NADPH oxidase and iNOS in the MPTP model of Parkinson's disease. J Neurol Sci 348: 142-152, 2015.

17. Hu L, Yu T and Jia Z: Experimental study of the protective effects of Astragalus and Salvia miltiorrhiza bunge on glycerol induced acute renal failure in rabbits. Zhonghua Wai Ke Za Zhi 34: 311-314, 1996 (In Chinese).

18. Sun XG, Fu XQ, Cai HB, Liu Q, Li CH, Liu YW, Li YJ, Liu ZF, Song YH and Lv ZP: Proteomic analysis of protective effects of polysaccharides from Salvia miltiorrhiza against immunological liver injury in mice. Phytother Res 25: 1087-1094, 2011.

19. Chen X, Guo J, Bao J, Lu J and Wang Y: The anticancer properties of Salvia miltiorrhiza Bunge (Danshen): a systematic review. Med Res Rev 34: 768-794, 2014.

20. Cui L, Li T, Liu Y, Zhou L, Li P, Xu B, Huang L, Chen Y, Liu Y, Tian X, et al: Salvianolic acid B prevents bone loss in prednisone-treated rats through stimulation of osteogenesis and bone marrow angiogenesis. PLoS One 7: e34647, 2012.

21. Jiang Y, Wang L, Zhang L, Wang T, Zhou Y, Ding C, Yang R, Wang $X$ and $Y u$ L: Optimization of extraction and antioxidant activity of polysaccharides from Salvia miltiorrhiza Bunge residue. Int J Biol Macromol 79: 533-541, 2015.

22. Qiang G, Yang X, Shi L, Zhang H, Chen B, Zhao Y, Zu M, Zhou D, Guo J, Yang H, et al: Antidiabetic effect of salvianolic acid A on diabetic animal models via AMPK activation and mitochondrial regulation. Cell Physiol Biochem 36 395-408, 2015.

23. Jin Q, Jiang S, Wu YL, Bai T, Yang Y, Jin X, Lian LH and Nan JX: Hepatoprotective effect of cryptotanshinone from Salvia miltiorrhiza in D-galactosamine/lipopolysaccharide-induced fulminant hepatic failure. Phytomedicine 21: 141-147, 2014.

24. Lv H, Wang L, Shen J, Hao S, Ming A, Wang X, Su F and Zhang Z: Salvianolic acid B attenuates apoptosis and inflammation via SIRT1 activation in experimental stroke rats. Brain Res Bull 115: 30-36, 2015.
25. Sonis ST, Tracey C, Shklar G, Jenson J and Florine D: An animal model for mucositis induced by cancer chemotherapy. Oral Surg Oral Med Oral Pathol 69: 437-443, 1990.

26. Florin A, Maire M, Bozec A, Hellani A, Chater S, Bars R, Chuzel F and Benahmed M: Androgens and postmeiotic germ cells regulate claudin-11 expression in rat Sertoli cells. Endocrinology 146: 1532-1540, 2005.

27. Blijlevens NM: Cytotoxic treatment-induced gastrointestinal symptoms. Curr Opin Support Palliat Care 1: 16-22, 2007.

28. Stringer AM and Logan RM: The role of oral flora in the development of chemotherapy-induced oral mucositis. J Oral Pathol Med 44: 81-87, 2015.

29. Nonzee NJ, Dandade NA, Patel U, Markossian T, Agulnik M, Argiris A, Patel JD, Kern RC, Munshi HG, Calhoun EA, et al: Evaluating the supportive care costs of severe radiochemotherapy-induced mucositis and pharyngitis: results from a Northwestern University Costs of Cancer program pilot study with head and neck and nonsmall cell lung cancer patients who received care at a county hospital, a Veterans administration hospital, or a comprehensive cancer care center. Cancer 113: 1446-1452, 2008

30. Ahmed KM: The effect of olive leaf extract in decreasing the expression of two pro-inflammatory cytokines in patients receiving chemotherapy for cancer. A randomized clinical trial. Saudi Dent J 25: 141-147, 2013.

31. Evrard A, Cuq P, Robert B, Vian L, Pèlegrin A and Cano JP: Enhancement of 5-fluorouracil cytotoxicity by human thymidine-phosphorylase expression in cancer cells: in vitro and in vivo study. Int J Cancer 80: 465-470, 1999.

32. Kodach LL, Bos CL, Durán N, Peppelenbosch MP, Ferreira CV and Hardwick JC: Violacein synergistically increases 5-fluorouracil cytotoxicity, induces apoptosis and inhibits Akt-mediated signal transduction in human colorectal cancer cells. Carcinogenesis 27: 508-516, 2006

33. Criswell T, Leskov K, Miyamoto S, Luo G and Boothman DA Transcription factors activated in mammalian cells after clinically relevant doses of ionizing radiation. Oncogene 22 : 5813-5827, 2003

34. Mendoza G, Alvarez AI, Pulido MM, Molina AJ, Merino G, Real R, Fernandes P and Prieto JG: Inhibitory effects of different antioxidants on hyaluronan depolymerization. Carbohydr Res 342: 96-102, 2007.

35. Kaji H, Inukai Y, Maiguma T, Ono H, Teshima D, Hiramoto K and Makino K: Radical scavenging activity of bisbenzylisoquinoline alkaloids and traditional prophylactics against chemotherapy-induced oral mucositis. J Clin Pharm Ther 34: 197-205, 2009

36. Erstad DJ and Cusack JC Jr: Targeting the NF- $\mathrm{BB}$ pathway in cancer therapy. Surg Oncol Clin N Am 22: 705-746, 2013.

37. Lappas M, Permezel M and Rice GE: N-acetyl-cysteine inhibits phospholipid metabolism, proinflammatory cytokine release, protease activity, and nuclear factor-kappaB deoxyribonucleic acid-binding activity in human fetal membranes in vitro. J Clin Endocrinol Metab 88: 1723-1729, 2003.

38. Bamba S, Andoh A, Yasui H, Araki Y, Bamba T and Fujiyama Y: Matrix metalloproteinase-3 secretion from human colonic subepithelial myofibroblasts: role of interleukin-17. J Gastroenterol 38: 548-554, 2003

39. Curra M, Martins MA, Lauxen IS, Pellicioli AC, Sant'Ana Filho M, Pavesi VC, Carrard VC and Martins MD: Effect of topical chamomile on immunohistochemical levels of IL-1 $\beta$ and TNF- $\alpha$ in 5-fluorouracil-induced oral mucositis in hamsters. Cancer Chemother Pharmacol 71: 293-299, 2013. 